\title{
Testing on Axial Compression of RC Columns Reinforced by Different Methods of Winding Steel Wire
}

\author{
SI Jianhui ${ }^{1, \mathrm{a}}$, LIU Bin ${ }^{1, \mathrm{~b}}$ and LIU Maoshe ${ }^{1, \mathrm{c}}$ \\ ${ }^{1}$ School of Civil Engineering and Architecture, Xi' an University of Technology china \\ asjhfr@163.com¹,549067758@qq.com,cliumaoshe@xaut.edu.cn
}

\begin{abstract}
The effects on ductility of RC columns reinforced by different methods of winding steel wire was studied through testing axial compression of RC columns by winding steel wire. Four groups of specimens of RC columns reinforced by winding steel wire were tested for axial compressions, in which one group was unreinforced RC columns; the others were RC columns reinforced by winding steel wire. Both of horizontally-wound and helically-wound reinforcement methods were adopted and, winding spacings were $100 \mathrm{~mm}$ and $50 \mathrm{~mm}$ respectively, the load-bearing capacity and ductility of RC columns were researched under two reinforcement methods and different winding spcings. The testing results showed that the load-bearing capacity of RC columns reinforced by winding steel wire could not improve greatly, however, the ductility of RC columns could be improved larger. Moreover, comparing with the horizontally-wound method, the helically-wound method could increase the ductility of RC columns better, in addition, the smaller the winding spacing was, the greater the ultimate load and peak strain of RC columns could be.
\end{abstract}

\section{Introduction}

Along with the rapid development and successful application of reinforcement technology in buildings in China, there have been a lot methods in reinforcing $\mathrm{RC}$ columns, for instance, enlarging section, pasting fiber composite materials and, winding steel wire, encasing with high-tensile steel wire mesh-composite mortar, etc.[1-6]. The studies on mechanical properties for reinforced structure both home and abroad are mainly concentrated on the calculation of load-bearing capacity, the studies on ductility and dynamic properties for reinforced structure are still insufficient [7]. The paper will mainly explore the effects on ductility of RC columns through the testing of reinforcing by winding steel wire and, provide a basis for engineering practical application of reinforcing technology by winding steel wire.

\footnotetext{
*Corresponding author: sjhfr@163.com
} 


\section{Testing}

\subsection{Specimens Design}

In accordance with Chinese Code for Design of Concrete Structures (GB 50010-2010), and Code for Design of Strengthening Concrete Structure (GB 50367-2013) [8-9], the design for specimens is as the follows: $4 \mathrm{RC}$ columns are chosen with slenderness ration $\mathrm{L}_{0} / \mathrm{b}=5$ for testing, in which 1 is compared column, the other 3 are columns reinforced by winding steel wire, the section of columns is given as $240 \mathrm{~mm} \times 240 \mathrm{~mm}$, the height is $1200 \mathrm{~mm}$, concrete grade is $\mathrm{C} 30$, the thickness of protection layer is $25 \mathrm{~mm}$, longitudinal bars HRB335 are used, 4 bars are placed, the diameter of longitudinal bars is $12 \mathrm{~mm}$, stirrups are HPB300, the stirrups are set close at both ends of columns with the spacing $100 \mathrm{~mm}$, in the middle of columns the spacing of stirrups is $150 \mathrm{~mm}$, the steel plates with the section of $240 \mathrm{~mm} \times 240 \mathrm{~mm}$, and the thickness of $10 \mathrm{~mm}$ are put at the both ends of columns, the specimens design is shown as Fig.1.

Strain gauges are mainly placed on the longitudinal bars, stirrups and the surface of RC columns. The strain gauges at stirrups are laid up and down symmetrically at the section A along the middle of columns, There are 22 strain gauges placed on the stirrups of each column, 1 gauge is laid in the middle of each longitudinal bar, and 1 gauge in the middle of every surface of each column, which is shown as Fig.1, these gauges are used to test the strain variation of concrete, longitudinal bars and stirrups when the RC columns are compressed.
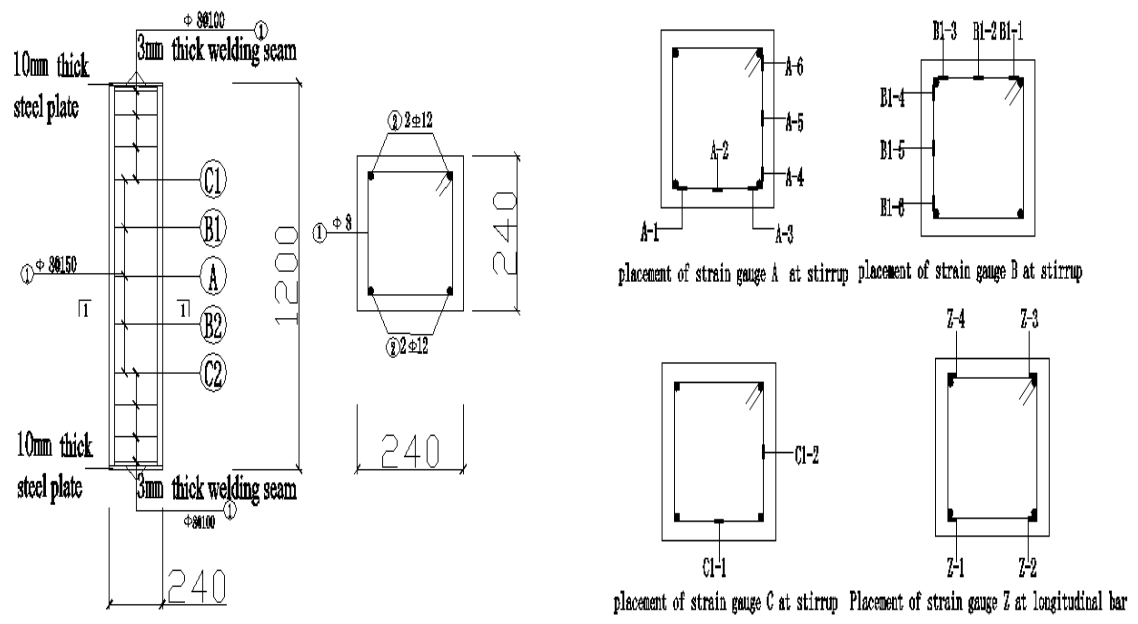

Fig.1 Specimens design

\subsection{Reinforcement Plan by Winding Steel Wire}

In the testing, galvanized steel wire rope with normal diameter $5 \mathrm{~mm}$ is adopted, the selected rope keeps suitable section in size, soft in form and, wound easily. The main variable parameters in testing are the winding spacing and winding methods of steel rope, when winding, hand operation is taken, and two winding methods are adopted, one is horizontally-wound method, it goes as the follows: surface treatment $\rightarrow$ winding horizontally a circle $\rightarrow$ fixing steel wire rope $\rightarrow$ initially fastening steel wire rope, then, the above steps are repeated according to the preset spacing, till the whole column shaft is 
wound. Another wind method is as the follows: surface treatment $\rightarrow$ fixing one end of steel wire rope $\rightarrow$ winging the steel wire rope through the whole column shaft $\rightarrow$ initially fastening steel wire rope $\rightarrow$ fixing another end of steel wire rope, the winding methods are shown as Fig.2. When treating the surface, sand paper is used to polish the rough places of the surfaces of column, then, cleaning the dust. The purpose of initially fastening steel wire rope is to make the steel wire rope restrain the circumferential deformation of concrete during the axial compression testing, thus, the hand operation is take to stretch the steel wire rope till it is tightened close with the surface of concrete, the both ends of rope are fixed with matched fasteners, tightened with spanner [10].

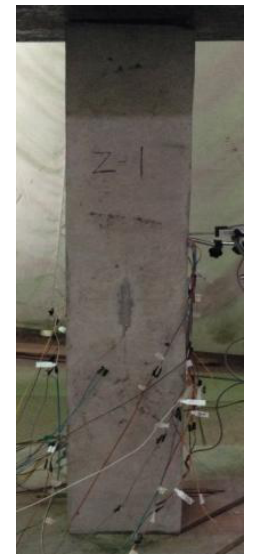

(a)Compared column

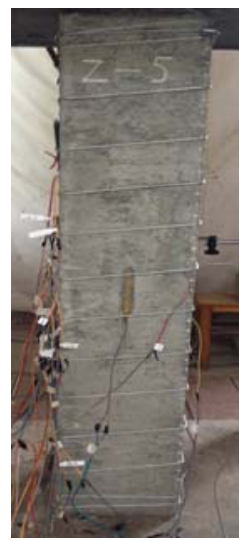

(c)Winding spacing with $100 \mathrm{~mm}$ of circumferential method

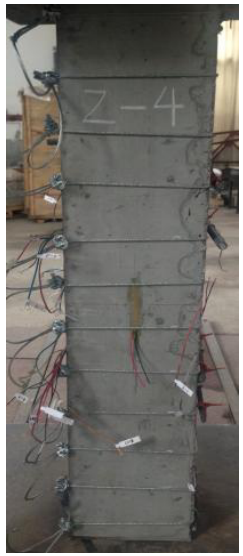

(b)Winding spacing with $100 \mathrm{~mm}$ of horizontally-wound method

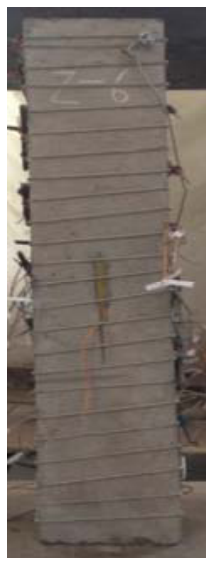

(d)Winding spacing with $50 \mathrm{~mm}$ of circumferential method

Fig.2 The winding methods

\subsection{Testing Loading}

The testing was carried out with 500t hydraulic servo long column machine at Xi'an University of Technology. Static data acquisition instrument TDS-303 was used for strain 
collection. Testing machine was shown as Fig.3, when testing, preloading was given at the speed of $1 \mathrm{KN} / \mathrm{s}$, then completed when the load reached to $0.3 \mathrm{Nu}(\mathrm{Nu}$ referring to estimated ultimate load), during this process the strain gauges and displacement gauges were examined to make sure if they were working normally, meanwhile, adjusting the centering of specimens. Formal loading at initial state was displacement control loading, the loading speed was $0.5 \mathrm{~mm} / \mathrm{min}$, when the RC column was compressed totally by testing machine, the loading was changed as force control loading, loading speed was $1 \mathrm{KN} / \mathrm{s}$, When approaching peak load, the displacement control loading was given, the loading speed was $0.2 \mathrm{~mm} / \mathrm{min}$, till the specimens were damaged. During testing, the data from strain gauges and displacement gauges were recorded in real time, the damage process and form were observed simultaneously.

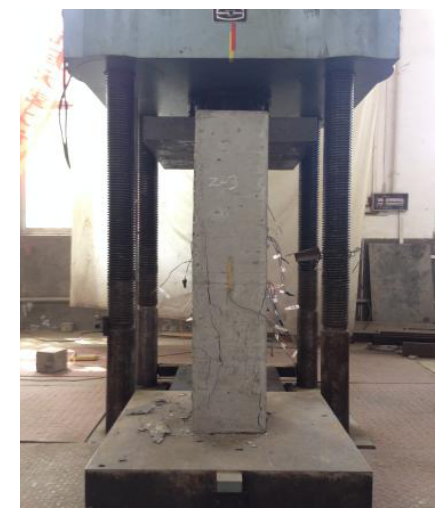

(a) Testing machine

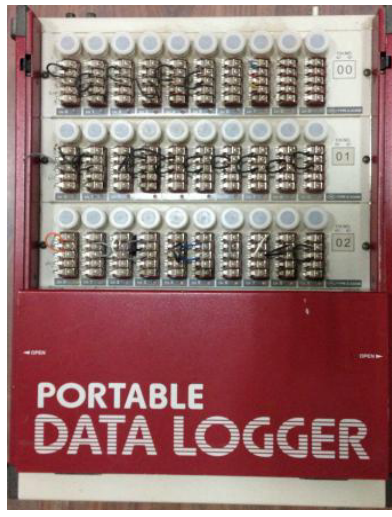

(b)date acquisition instrument

Fig.3 Testing machine and date acquisition instrument

\section{Testing Results and Analysis}

\subsection{Testing Phenomena}

During loading, tiny and vertical cracks appeared at each side of compared specimens, and these cracks initially appeared at both bottom and head of the specimens, along with the increasing of loading, these cracks began to extend in the middle of the specimens, meanwhile, concrete began to occur lateral bulging, when approaching peak load, the cracks increased in numbers and, the distributions of crack became much denser, the width of cracks enlarged and developed along vertical direction, then, the cracks from adjoining surfaces met together at the edges of RC column, along with the clear voice of cracking, small pieces of concrete dropped, when the loading added continuously, the falling blocks of concrete became much bigger and, the cracking voice was much louder, till the larger blocks of concrete fell and the steel bars were exposed, thus, the specimens were damaged.

In the process of loading reinforced RC columns, vertical cracks developed slowly, the numbers of cracks were less, when approaching peak load, there was just louder voice of cracks developing, and no falling of concrete blocks, after peak load, every reinforced specimen could still keep the load and, bear continuously axial compression deformation, when loading continued, steel wires at the edges sank into slowly the RC columns, larger cracks appeared at the RC columns, however, the RC columns still could maintain larger loading over a longer time, along with the loosing of each steel wire, the loading began to decline. Meanwhile, it could be found when the smaller the spacing of winding was, the 
smaller the broken blocks formed by the cracks on the surfaces of RC columns became, and the denser the cracks developed. The typical damaged forms of specimens were shown as Fig.4.

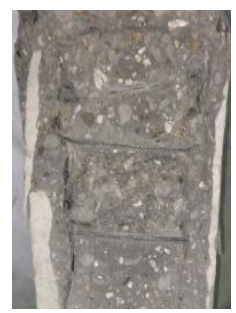

(a)Compared column

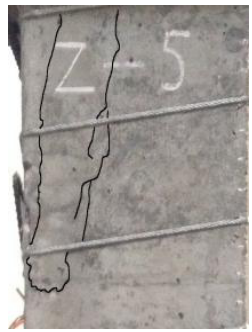

(c)Winding spacing with $100 \mathrm{~mm}$ of circumferential method

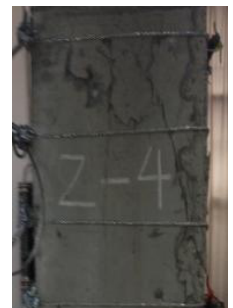

(b)Winding spacing with $100 \mathrm{~mm}$ of horizontally-wound method

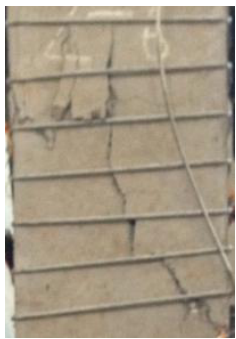

(d)Winding spacing with $50 \mathrm{~mm}$ of circumferential method

Fig.4 damaged forms of specimens

\subsection{Testing Data Analysis}

Reinforcing the damaged RC columns with steel wire can improve the load-bearing capacity (testing load parameters are shown as Tab. 1), when winding spacing is $100 \mathrm{~mm}$, the ultimate load of reinforced RC columns by horizontally winding steel wire increases by $5.4 \%$ in comparison with the compared specimens, the ultimate load of reinforced RC columns by helically winding increases by $9 \%$ relative to the compared specimens, thus, there is no big difference between both of horizontally-wound and helically-wound reinforcing methods, when winding spacing is $50 \mathrm{~mm}$, the ultimate load of RC columns reinforced by helically winding increases by $10 \%$, comparing with the compared specimens.

Reinforcing the damaged RC columns with steel wire can improve the ductility of concrete, longitudinal bars and stirrup. Taking the RC columns reinforced by helically winding steel wire as research target, when winding spacing is $100 \mathrm{~mm}$, for the horizontally-wound method, the strain of concrete increases by $29.6 \%$, and the strain of longitudinal bars raises by $23.8 \%$, the strain of stirrup increases by $12.1 \%$, for the helically-wound method, the strain of concrete increases by $39.8 \%$, and the strain of longitudinal bars raises by $26.5 \%$, the strain of stirrup increases by $15.8 \%$. When winding spacing is $50 \mathrm{~mm}$, for the helically-wound method, the stain of concrete raises by $69 \%$, and strain of longitudinal bars increases by $53.5 \%$ and, the strain of stirrup increases by $98 \%$. 
TAB.1 TESTING LOAD PARAMETERS

\begin{tabular}{ccc}
\hline Specimen number & winding spacings $/ \mathrm{mm}$ & Ultimate load $/ \mathrm{kN}$ \\
\hline Colunm1 & No & 1650 \\
Colunm2 & 100 (Horizontally-wound method) & 1672 \\
Colunm3 & 100 (Circumferential method) & 1700 \\
Colunm4 & 50 (Circumferential method) & 1740 \\
\hline
\end{tabular}

The load-displacement curves from the beginning of loading till the damage of specimens on axial compression of concrete specimens reinforced by winding steel wire are shown as Fig.5, due to the preload at long column machine, which leads to the loading of compared RC columns and RC columns reinforced with steel wire at the initial stage of compressing increases fast or slow, however, along with the increasing of load, the curves of displacement of compared columns and RC columns reinforced by winding steel wire present even increase in the process of axial compression, and reaching the different ultimate load gradually, when appearing the ultimate load, the load-displacement curve of compared columns declines faster, but the load-displacement curve of RC columns reinforced by winding steel wire declines flat relatively, reflecting fine ductile fracture. Under the same winding spacing, the load-displacement curve of helically-wound reinforced $\mathrm{RC}$ columns at the declining stage becomes much flatter than the horizontally-wound reinforced RC columns, in addition, with the same winding method, the smaller the winding spacing is, the better the ductile fracture of reinforced $\mathrm{RC}$ columns becomes.

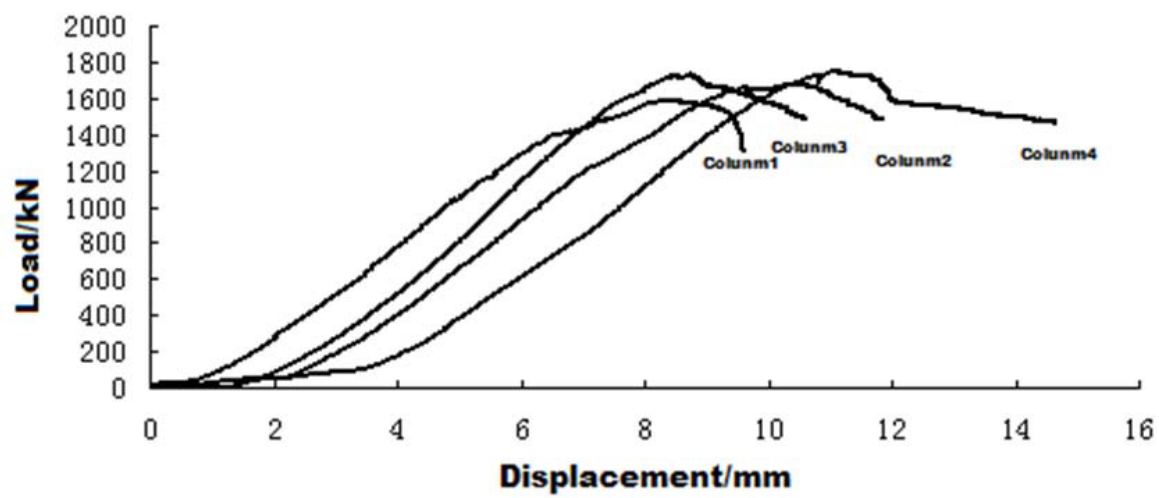

Fig.5 Load-displacement curve of specimens

The load-displacement curve of RC columns during compressing is shown as Fig.6. It can be seen that along with evenly increasing of load in the process of axial compression of non-reinforced RC columns, the strains at the surface of concrete as well as the middle of longitudinal bars raise evenly, the curve is close to a straight line, the strain of stirrup at the cracks of concrete increases straightly at the initial stage, when RC columns are compressed and till cracked, the strain raises slowly and the curve becomes bent, the strain reaches the peak value when the $\mathrm{RC}$ columns are compressed to ultimate load. It can be obtained from Fig. 6 that the strain has maximal value at the position of longitudinal bars; meanwhile, the strain of stirrup at the fracture has minimum value when RC columns are 
compressed to ultimate load.

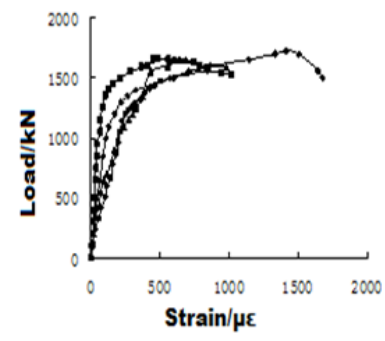

(a)Typical stirrup load-strain

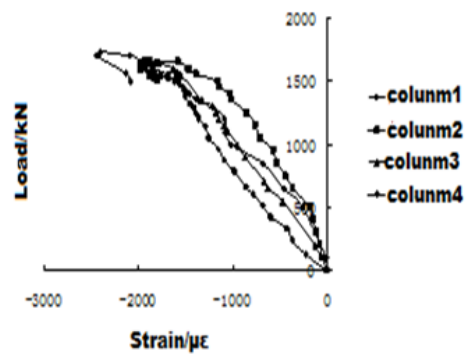

(b)Typical longitudinal bar load-strain

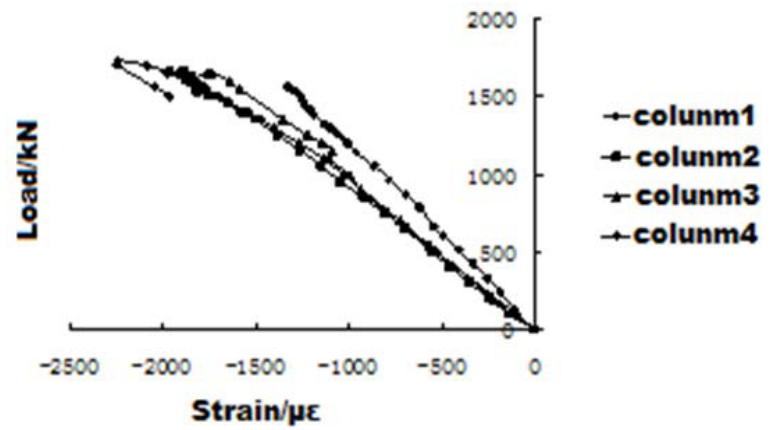

(c)Typical load-strain of concrete

Fig6.Load-strain curve of specimens

\section{Conclusions}

(1) Reinforcing the RC columns by winding steel wire can increase the load-bearing capacity of RC columns, the smaller the spacing of winding is, the larger the load-bearing capacity of RC columns becomes, but the increasing of load-bearing capacity is not in a big extent in general.

(2) Reinforcing the RC columns by winding steel wire can improve the ductility of concrete better, which means that the strain values at the surface of concrete, the longitudinal bars as well as the stirrup at fracture in the process of axial compression can be improved, too. The steel wire can restrain well the axial deformation of $\mathrm{RC}$ columns, in addition, it can delay the fracture of axial compression of RC columns and, only can the RC columns be damaged till the steel wire is broken.

(3) Both of helically-wound and horizontally-wound reinforcing methods are not obvious to the increase of load-bearing capacity of RC columns, therefore, it is difficult to compare the advantages and disadvantages of both reinforcing methods, as for the improvement of ductility of RC columns, the method of helically-wound winding is better than the horizontally-wound winding, which means that the increasing extents of strain values at surface of concrete, the longitudinal bars as well as the stirrup at fracture are all greater than that ones by horizontally-wound method.

\section{Acknowledgements}

Supported by Chinese National Natural Science Fund (51308455), Natural Science 
Project of Education Department of Shaanxi Province (15JK1522), Construction Science and Technology Planning Program of Xi'an City (SJW 2015-21), Science and Technology Innovation Planning Program of xi an university of technology 2015CX019.

\section{References}

1. Hegger J, Will N, Bruckermann O, et al. Loading-bearing Behavior and Simulation of Textile-reinforced Concrete [J]. Materials and Structures, 2006,39(8):765-776.

2. Larbi A S, Contamine R, Hamelin P. TRC and Hybrid Solutions for Repairing and Strengthening Reinforced Concrete Beams [J]. Engineering Structures, 2012,45:12-20.

3. Yin Shiping, Sheng Jie, Jia Shen. Testing Research of Fatigue Damage on RC Beams Reinforced with Textile Reinforced Concrete [J]. Journal of Building structures, 2015, 36( 4) : 86-92.

4. Lu Yiyan, Liang Hongjun, Li Bin, Yin Xiaoshan. Experimental study on behavior of square RC columns strengthened with self-compacting concrete filled square steel tubes under axial load [J]. Journal of Building structures, 2015, 36( 7) : 43-50.

5. Miao Jijun, Zeng Zaijun, Liu Yanchun, Liu Caiwei, Wang Junfu. Research on Behaviors of Concrete Members Strengthened by Basalt Fiber Reinforced Plastic Sheets Under Freeze-thaw Environment [J]. Journal of Building structures, 2010, ( s2) : 266-268.

6. Huang Jianfeng, Zhu Chunming, Gong Zhiguo, Zhang Fuwei. Experimental Study on Seismic Behavior of Earthquake-damaged RC Frame Strengthened by Enlarging Cross-section [J]. China Civil Engineering Journal, 2012,45 (12): 9-17.

7. Pan Mingyuan. Testing Research of RC columns reinforced by Winding Steel Wire [J].Concrete, 2008,(3):124-125.

8. GB 50010-2010 Code for Design of Concrete Structures [S].Beijing : China Architecture and Building Press, 2011.

9. GB 50367-2013 Code for Design of Strengthening Concrete Structure [S].Beijing: China Architecture and Building Press, 2013.

10. Wei Yang, Wu Gang, Zhang Min. Property Testing and Load-Bearing Capacity Calculation on Axial Compression of RC Columns Reinforced by Winding Steel Wire [J]. Building Structure, 2014, 44( 11) : 20-24. 